\title{
The diet of the European badger in a Mediterranean coastal area
}

\author{
Giorgio PIGOZZI*
}

Pigozzi G. 1991. The diet of the European badger in a Mediterranean coastal area. Acta theriol. 36: 293 - 306 .

The food of European badgers Meles meles Linnaeus, 1758 in a dry Mediterranean coastal habitat in central Italy was determined by faecal analysis. Between February 1983 and November 1985 badgers fed primarily on fruits and insects, which made up a combined volume of about $90 \%$ of the to'al amount of food eaten each year. Insects and fruits were exploited alternately, the former mainly during winter and spring whereas the latter mainly during summer and autumn.

A significant change in this pattern was found in autumn 1985 when the occurrence of insects was higher and that of fruits was lower, respectively, than in the previous years. Other less important food resources included myriapods, molluscs, birds and mammals. Earthworms did not play an important role in the diet in any period of the year. It is suggested that badgers might adjust to their seasonally fluctuating foods by changing their food choice so as to maximize their intake from the available resources.

University of Aberdeen, Department of Zoology, Culterty Field Station, Newburgh, Aberdeenshire AB40AA, Scotland

Key words: Meles meles, diet, Italy

\section{Introduction}

The food habits of the European badger, Meles meles Linnaeus, 1758 have been extensively studied in the central and northern part of Europe (e.g. Andersen 1955, Skoog 1970, Hancox 1973, Wiertz 1976, Kruuk and Parish 1981, Henry 1984, review in Pigozzi, in press and references therein). These studies have clearly shown that earthworms (Lumbricus spp.) often represent the main food resource exploited by badgers. Few studies have assessed the diet of badgers living in Mediterranean coastal habitats where prevailing environmental conditions (e.g. hot temperature, lack of rain, sandy soils, rich plant communities) are expected to reduce the potential availability of earthworms (cf. Edwards and Lofty 1977), to favour the availability of insects (Blondel 1969) and to vary the seasonal nutritional value and abundance of fruits (Herrera 1982). Martin-Franquelo (1984) and Ciampalini and Lovari (1985) have analysed the diet of badgers over a period of one year in two undisturbed coastal areas, the Dõnana National Park, Spain, and the Maremma Natural Park, Italy, respectively. Not surprisingly, both studies have shown the low occurrence of earthworms in the diet, which were replaced by rabbits (Oryctolagus cuniculus) in the Donãna National Park and by fruits and insects in the Maremma Natural Park.

The aim of this paper is to describe the diet and seasonal variation in the exploitation of food resources by the European badger over a three-year period in the Maremma Natural Park.

$\bullet$ Present address: Via S. Sofia 188, 21040 Cislago, Varese, Italy 


\section{Study area}

The Maremma Natural Park is located along the Tyrrhenian coast in the southern part of Tuscany, approximately $180 \mathrm{~km}$ north of Rome $\left(42^{\circ} 39^{\prime} \mathrm{N}, 11^{\circ} 05^{\prime} \mathrm{E}\right)$. The study area is in the inner part of the Park in a zone of $4 \mathrm{~km}$ not affected by human interference in the form of housing or agriculture. A canal divides the study area in two parts: the western side of the canal is covered with a dense pine forest (Pitius pinea and Pinus pinaster) and has a sandy soil, whereas the eastern side of the canal has a few grazing areas which end at a limestone ridge. The area above the limestone ridge is covered with a dense maquis, dominated by Quercus ilex, Quercus cerris. Arbutus unedo, and has a calcareous substrate. Detailed information on the vegetation communities are described in Arrigoni et al. (1976). The population density of badgers was low (approximately one adult individual/100 ha) but badgers occurred in all habitats included in the study area.

Climatological data were collected at a nearby observatory in Grosseto, approximately $10 \mathrm{~km}$ north of the study area. There are three climatological periods: cold period (December to March, mean temperature $<11^{\circ} \mathrm{C}$ ), mild period (April and May, October and November, mean temperature between 11 and $19^{\circ} \mathrm{C}$ ) and hot period (June to September, mean temperature $>19^{\circ} \mathrm{C}$ ). Rainfall $(700-800 \mathrm{~mm}$ per year) tends to be seasonal, being abundant in late winter and autumn while almost absent in summer.

\section{Materials and methods}

\section{Diet analysis}

Faeces were collected during systematic surveys of known defecation sites at two-weekly intervals from February 1983 to November 1985. Faeces of uncertain age (older than 4 weeks) were excluded from this analysis in order to obtain a representative sample for each month (Pigozzi 1990). The collection of faeces usually lasted 2 days, with care taken to keep the search effort constant throughout the study. An attempt was made to take each sample from only one defecation. This was done by noticing the water content, different colour and distinct shape of each portion of the defecation. On a few occasions, it was not possible to discriminate between different portions and, accordingly, the defecation was scored as a single faeces. The date of collection, location, and a description of the defecation site (i.e. in pit sensu Kruuk (1978) or on the ground) were recorded.

Faeces were placed in a polythene bag and stored at a constant temperature $\left(3^{\circ} \mathrm{C}\right)$ in a refrigerator at the Istituto Zooprofilattico (Grosseto) until processing. Faecal analysis was performed according to the procedure employed by Kruuk and Parish (1981). A solution of $2 \%$ formalin was added to each dropping to loosen its contents. Then the soaked material was sieved in a $1.5 \mathrm{~mm}$ wire-mesh sieve and carefully washed under tap water. All components passing through the sieve during the rinsing were collected in a bowl. About 10 inin later, when the solid material had settled, a sample of approximately $2 \mathrm{ml}$ was taken from the bottom of the bowl using a wide-bore pipette. This sample was washed in a Petri-dish and carefully examined for the presence of earthworm chaetae. The larger components of the faeces retained in the sieve were thoroughly washed until the water passing through them was clear, then they were analysed under water in a large white tray and sorted macroscopically. All food remains were compared with a reference collection taken from the study area. Earthworms were identified by the presence of chaetae, insects by the presence of diagnostic remains (head-capsules, fore legs, hind legs, elytrae, wings, mandibles), molluscs by the presence of the rudiment of the shell (slugs) or fragments of the shell (snails), amphibians by the presence of their characteristic light and thin bones, reptiles by the presence of their skins, birds by the presence of feathers with reference to Day (1966), mammals by the presence of their teeth and mandibles with reference to Toschi (1965) and hair with reference to Debrot et al. (1982), and vegetable foods by the presence of seeds, undigested soft and hard parts of the fruit. In most cases the identification proceeded to the genus or species level, otherwise ordinal or family level was used.

The number of individual food items present in the faeces was estimated according to the following procedures. The number of earthworms was estimated according to the technique suggested by Kruuk and Parish (1981). The sample taken from the sediment was carefully examined under a $40 \mathrm{x}$ binocular microscope 
and the number of chaetae found in 60 randomly chosen fields (a total area of approximately $10 \mathrm{~cm}^{2}$ ) was recorded. The mean number of chaetae per $\mathrm{cm}^{2}$ was given a score according to the scale used by Kruuk and Parish (1981). The diagnostic remains of insects (e.g. head-capsules, mandibles, legs, abdomen, etc.) found in the faeces were separated, identified and counted. Since each diagnostic fragment did not necessarily come from a different individual, a correction factor was applied. The number derived from the count of legs was divided by 6 , unless they formed a specialized pair (e.g. fore legs of mole-crickets, hind legs of grasshoppers), in which case they were divided by 2 . Head-capsules and distal segments of the abdomen (i.e. telson) each represented one individual prey item. The values obtained after applying the correction factors were compared and the highest value was considered as the estimate of the number of insects eaten (Calver and Wooller 1982). This comparison was done for each kind of insect present in the faeces. The cephalic and abdominal segments of Myriapods were separated and counted and the highest value was considered as the estimate of the number of individuals eaten. The rudiment of the shell of slugs was separated and counted and the value obtained was considered as the estimate of the number of individuals eaten. The seeds of fruits were counted and the value obtained was used to make an estimate of the number of fruits eaten (e.g. olives). The number of stalk attachments was counted and considered as the estimate of the number of strawberry-tree fruits eaten. The seeds of Juniperus oxycedrus macrocarpa were counted and this value was divided by 3 . The result represented the estimate of the number of berries eaten.

Two different measures were used: frequency of occurrence (\%) and estimated volume (\%). The frequency of occurrence of a food represented the percentage of samples in which a given food item occurred. The estimated volume (\%) represented the relative volume of each kind of food eaten by badgers. It was computed as suggested by Kruuk and Parish (1981). The relative volume of each kind of food eaten was given a percentage value based on a seven point scale: 0 (food not found in the faeces), 1 (estimated volume less than 5\%), 2 (6 - 25\%), 3 (26 - 50\%), 4 (51 - 75\%), 5 (76 - 95\%), 6 (over 95\%). The estimated volume of similar kinds of foods (e.g. beetles, grasshoppers, etc.) were summed together into broader food categories (e.g. Insecta). The following food categories were used: Annelida, Myriapoda, Insecta, Mollusca, Amphibia, Fruits, Grass, and Other.

Aves, Mammalia

Fig. 1. Number of faeces collected in the Maremma Natural Park between February 1983 and November 1985.

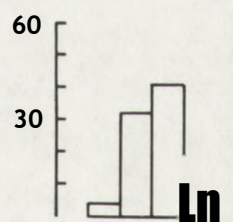

1983

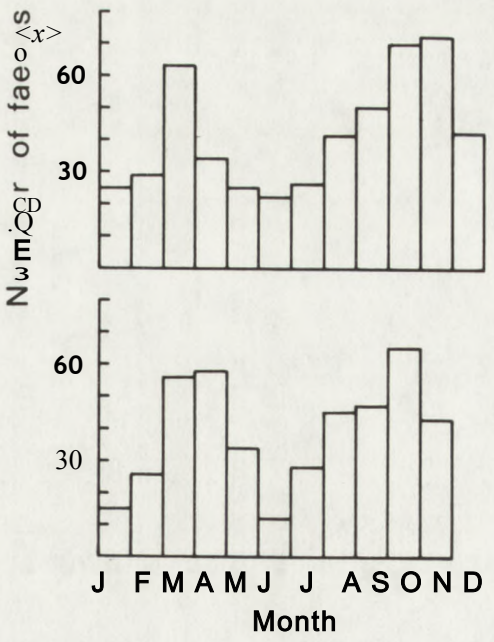


Table 1. Kendall rank correlation coefficients (т) among frequency of occurrence (\%) of different food resources in the diet, faecal sample size, mean temperature and rainfall in each month between February 1983 and November $1985(\mathrm{~N}=33)$.

\begin{tabular}{|c|c|c|c|c|c|c|c|c|c|c|}
\hline & Anne & Myri & Inse & Moll & Amph & Aves & Mamm & Frui & Gras & Othe Faec Temp \\
\hline Myri & $0.43 * * *$ & & & & & & & & & \\
\hline Inse & $-0.39 * *$ & -0.16 & & & & & & & & \\
\hline Moll & -0.06 & -0.18 & 0.10 & & & & & & & \\
\hline Amph & 0.13 & -0.03 & -0.06 & -0.03 & & & & & & \\
\hline Aves & 0.00 & 0.05 & 0.04 & $-0.26^{*}$ & -0.19 & & & & & \\
\hline Mamm & 0.36 & $0.50 * * *$ & -0.12 & -0.06 & -0.09 & -0.06 & & & & \\
\hline Frui & 0.19 & 0.05 & $-0.49 * * *$ & 0.00 & 0.22 & -0.19 & 0.17 & & & \\
\hline Gras & 0.25 & 0.09 & -0.07 & 0.08 & 0.10 & 0.14 & -0.05 & -0.16 & & \\
\hline Othe & 0.15 & 0.12 & $-0.37 * *$ & -0.08 & 0.08 & 0.02 & 0.22 & $0.31 *$ & -0.03 & \\
\hline Faec & 0.10 & -0.01 & -0.23 & 0.16 & $0.34 * *$ & -0.08 & -0.03 & $0.26^{*}$ & 0.06 & 0.31 \\
\hline Temp & $-0.67 * * *$ & $-0.50 * * *$ & $0.33 * *$ & 0.10 & -0.04 & -0.03 & $-0.46 * * *$ & -0.14 & -0.12 & -0.110 .05 \\
\hline Rain & $0.31 *$ & $0.26^{*}$ & -0.19 & -0.08 & 0.07 & -0.01 & 0.17 & 0.19 & 0.09 & $0.35 * * 0.12-0.27 *$ \\
\hline
\end{tabular}

Anne - Annelida, Myri - Myriapoda, Inse - Insecta, Moll - Mollusca, Amph - Amphibia, Aves - Aves, Mamm - Mammalia, Frui - Fruits, Gras - Grass, Othe - Other, Faec - Faecal sample size, Temp - mean temperature, Rain - Rainfall. * $-p<0.05, * *-p<0.01, * * *-p<0.001$ (two tailed test). 


\section{Results}

\section{Faccal sample size}

The number of faeces collected per month, between February 1983 and November 1985 $(\mathrm{N}=1230)$, showed a bimodal distribution, with peaks in March - April and October November. Fewest faeces were consistently collected in June, between 0 and 72 and such a pattern was consistent throughout the study (Fig. 1). The number of faeces collected per month was not correlated with either monthly mean ambient temperature or the monthly rainfall. However, the correlation between the number of faeces collected in each month and the frequency of occurrence of fruits, amphibians, and other foods proved significant and that with insects approached significance (Table 1). The number of faeces collected in each season, i.e. winter ( $\mathrm{J}$ - M), spring (A - J), summer ( J - S), autumn (O - D), was significantly different among years $\left(\%^{2}=18.3\right.$, d.f. $\left.=6, p<0.01\right)$, due mainly to fewer faeces collected in winter 1983. When taking into account the effect of experience in collecting faeces (i.e. excluding
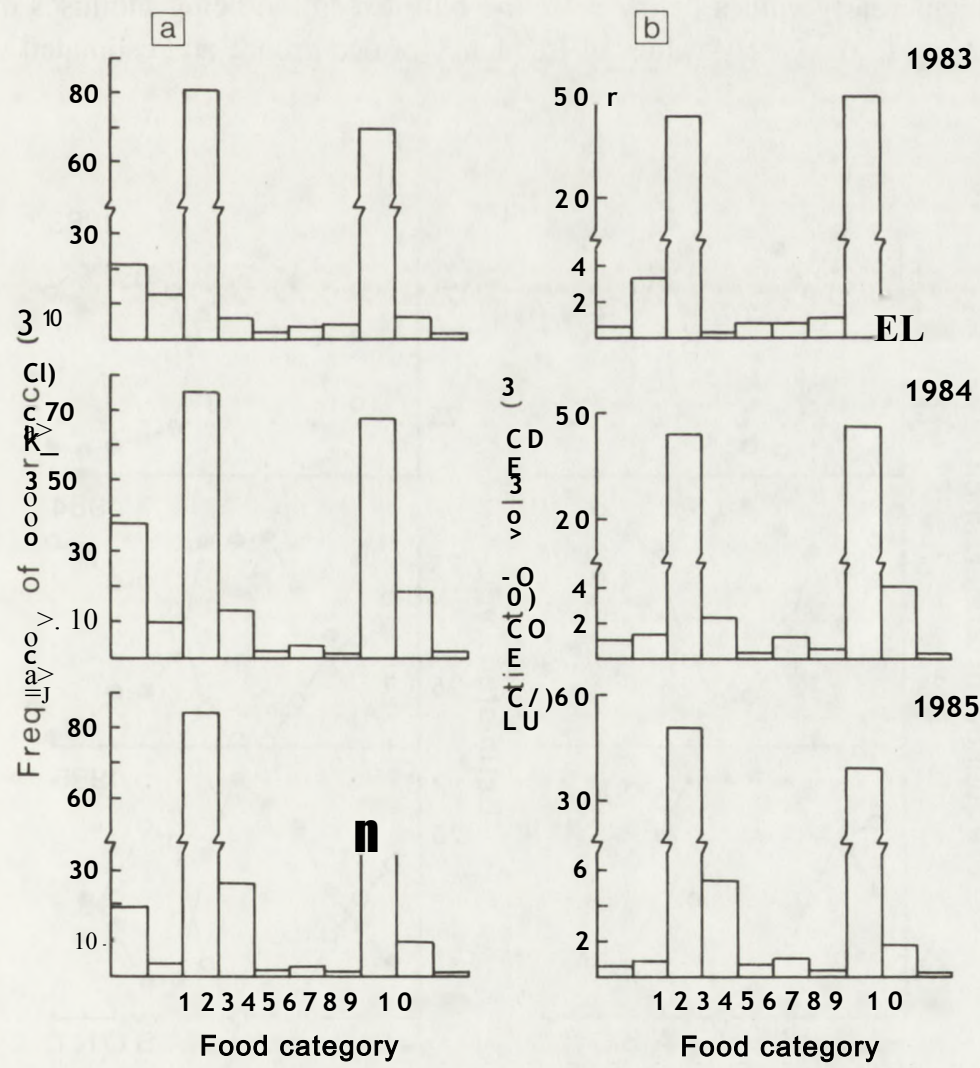

Fig. 2. The various categories of food of the badger in the Maremma Natural Park during 1983 - 85. (a) Frequency of occurrence (\%) in faeces, (b) percentage estimated volume in the diet. 1 - Annelida, 2 - Myriapoda, 3 - Insecta, 4 Mollusca, 5 - Amphibia, 6 - Aves, 7 - Mammalia, 8 - Fruits, 9 - Grass, 10 - Other. 
the 1983 data) no significant difference was found between years $(\%$ 2 $0.05)$.

\section{Annual diet}

The percentage frequency of occurrence of each food category found in badger faeces is shown in Figure 2a. In each year fruits and insects were by far the most common foods eaten by badgers. The yearly value ranged between $74.5 \%$ (1984) and $84.2 \%$ (1985) for insects and between $59.1 \% \quad(1985)$ and $69.8 \%$ (1983) for fruits. All the other food categories were of secondary importance. The yearly value of occurrence of earthworms ranged between 19.2\% (1985) and $38.1 \%$ (1984), that of slugs between $5.4 \%$ (1983) and $26.1 \%$ (1984), that of myriapods between $3.7 \%$ (1985) and $12.5 \%$ (1983). Amphibians, birds, and mammals had yearly values of occurrence less than $4 \%$. The estimated volume of each food category is shown in Figure 2b. Fruits and insects made the bulk of food with a combined volume approaching $90 \%$ in any year. The yearly value ranged between $42.5 \%$ (1983) and $50.6 \%$ (1985) for insects and between $38.9 \%$ (1985) and $48.5 \%$ (1983) for fruits. The other food categories all had yearly values below $5 \%$, the only exception being molluscs during 1985 (5.4\%). According to the yearly values of frequency of occurrence and estimated volume, the

a

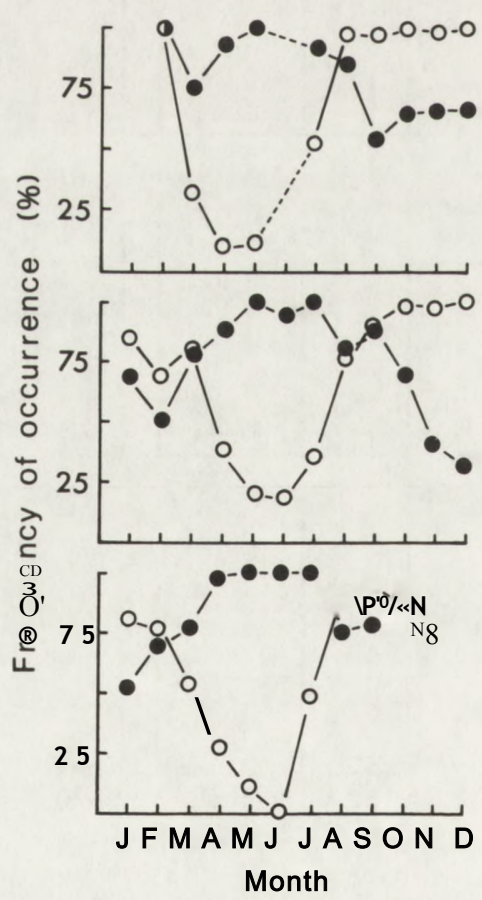

b

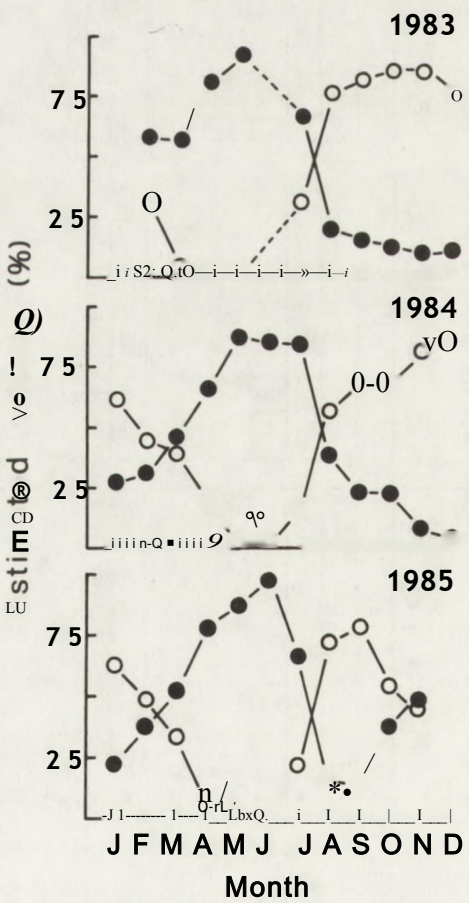

Fig. 3. (a) Frequency of occurrence (\%) and (b) estimated volume (\%) of insects $(\bullet)$ and fruits $(\mathrm{O})$ in the diet of the badger in the Maremma Natural Park between February 1983 and November 1985. 
food resources were divided into principal (insects and fruits) and secondary categories (the remaining foods).

\section{Principal food categories}

The monthly frequency of occurrence of insects was correlated with the monthly mean temperature but not with the monthly rainfall (Table 1). On the other hand the monthly frequency of occurrence of fruits was not correlated with either the monthly mean temperature or the monthly rainfall (Table 1). Furthermore, if the effect of the monthly faecal sample size was held constant, the correlation between the monthly frequency of occurrence of insects and fruits was $\mathrm{x}=-0.45$, not much smaller than that obtained when the monthly faecal sample size was not partialled out $(\mathrm{t}=-0.49, \boldsymbol{p}<0.001)$. This suggests that the relation between frequency of occurrence of insetcs and fruits was relatively independent of the influence exerted by the monthly faecal sample size.

\section{Insects}

The frequency of occurrence of insects was highly seasonal with a peak during April June (Fig. 3a). The seasonal occurrence of insects during winter, spring, and summer was not different among the three years $(\boldsymbol{p}>0.30)$. Conversely, the occurrence of insects in autumn was significantly higher in 1985 than in the previous years $(\boldsymbol{p}<0.001)$. The estimated volume reflected the same pattern with high values during spring and low values during autumn (Fig. 3b). This pattern was consistent throughout the study, the only exception being autumn 1985, which did not present the usual decrease in the estimated volume as in the previous years. The insects found in the faeces were divided into the following categories: Coleoptera (larvae and adults), Orthopterci (adults), Hemiptera (larvae) and Lepidoptera (caterpillars).

Table 2. Frequency of occurrence (\%) of a given principal food resource and percentage of faeces in which that food resource had an estimated volume $>50 \%$ during the peak period of exploitation in 1984 and 1985.

\begin{tabular}{llcc}
\hline Item & $\begin{array}{c}\text { Peak } \\
\text { period }\end{array}$ & $\begin{array}{c}\text { Frequency of } \\
\text { occurrence, } \%\end{array}$ & $\begin{array}{c}\text { Faeces vol. } \\
\%\end{array}$ \\
\hline $\begin{array}{l}\text { Insect a } \\
\text { Coleptera larvae }\end{array}$ & & & \\
Scarabaeidae adult & Apr. 85 & 79 & 80 \\
Carabidae adult & July 85 & 93 & 23 \\
Orthoptera adult & June 84 & 45 & 10 \\
Hemiptera & July 85 & 39 & 18 \\
Lepidoptera & May 85 & 82 & 68 \\
Fruits & Mar 85 & 37 & 33 \\
Juniperus macrocarpa & & & \\
Rubus ulmifolius & Oct 84 & 81 & 65 \\
Arbutus unedo & Aug 85 & 87 & 82 \\
Quercus spp. & Nov 84 & 50 & 81 \\
Olea europaea & Jan 84 & 68 & 53 \\
\hline
\end{tabular}


Coleóptera larvae [Lamellicornia larvae (Scarabcieidae: Melolonthinae, Geotrupinae, Coprinae)] were important food items during spring, and to a lesser degree in autumn. They reached a peak in March - April when $80 \%$ of the faecal sample analysed was made up by these larvae (Table 2). During spring Hemiptera (Cicada larvae) and caterpillars (Lepidoptera) were important food resources, making the bulk of the diet in May and March, respectively (Table 2), while in summer Orthoptera and adults of Coleoptera were heavily preyed upon by badgers. Coleoptera adults (Scarabaeidae, mainly Geotrupes niger, Geotrupes spiniger and Carabidae, mainly Calosoma sicophanta, Cetonia aurata, Potosia cupred) were exploited primarily during late spring and summer. Scarabaeidae (mainly Geotrupes spp.) reached a peak in July when their estimated volume was over $50 \%$ in half of the analysed faecal sample. Both Carabidae and Orthoptera (mainly adult grasshoppers, Calliptamus italicus), reached a peak in early summer although their contribution, in terms of volume of food eaten by badgers, was negligible in comparison with that of other insects (Table 2).

\section{Fruits}

The frequency of occurrence of fruits was highly seasonal with a peak during October December (Fig. 3a). Unlike insects, the seasonal occurrence of fruits was different among years, the only exception being spring $(/ ;>0.05)$. In summer their occurrence was significantly lower in 1984 than in the other years $(\boldsymbol{p}<0.01)$, in autumn their occurrence was significantly lower in $1985(/><0.001)$, and in winter their occurrence was significantly lower in 1983 ( $p$ $<0.001)$. The estimated volume usually reached a high value during late summer and autumn. This pattern was consistent throughout the study, the only exception being autumn 1985 when the estimated volume of fruits showed a sharp decline in comparison with the previous years (Fig. 3b). Several kinds of fruits were found in the faeces but the most common were juniper, blackberry, and strawberry-tree fruits. Blackberry (Rubus ulmifolius) was a major component of the diet in the summer period. The frequency of occurrence of blackberries reached a peak in August (1985) and in September (1984) when they played a major role in the diet (Table 2). Berries of Juniperus oxycedrus macrocarpa and of Juniperus phoenicea were both eaten by badgers but the latter were found in less than $2 \%$ of the faeces. Juniper berries were found in any month although their frequency was higher during autumn, and, to a lesser degree, in winter. The exploitation of juniper berries reached a peak in October when they were the most important component of the diet (Table 2). Strawberry-tree fruits (Arbutus unedo) were an important food resource in the autumn. The frequency of occurrence of strawberry-tree fruits usually reached a peak in November when they made up the bulk of the food eaten by badgers (Table 2).

\section{Secondary food categories}

Annelida: the monthly frequency of occurrence of earthworms not surprisingly was negatively correlated with the monthly mean temperature and positively with the monthly rainfall (Table 1). Moreover, the monthly frequency of occurrence of earthworms was positively correlated with that of myriapods, mammals and grass, and negatively with that of insects (Table 1). The frequency of occurrence of earthworms (Lumbricidae) in the diet was highly seasonal (Fig. 4a) with a peak during winter and small values in the summer period. 
The estimated volume reflected a similar pattern (Fig. 5a) with very small monthly values (less than $3 \%)$.

Myriapoda: the monthly frequency of occurrence of myriapods was negatively correlated with the monthly mean temperature and positively with the monthly rainfall (Table 1). Moreover, the monthly frequency of occurrence of myriapods was correlated with that of mammals and earthworms (Table 1). The frequency of occurrence of myriapods (Geophilidae and Scolopendridae) in the diet was seasonal with a peak during winter and reduced values during the summer period (Fig. 4b). The estimated volume showed a similar pattern (Fig. 5b) with very small values (less than 5\%), with the exception of late winter and spring 1983.

\section{3}

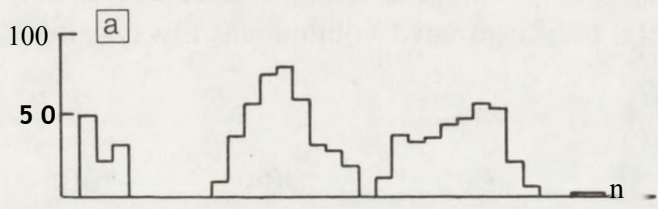

$50-b$

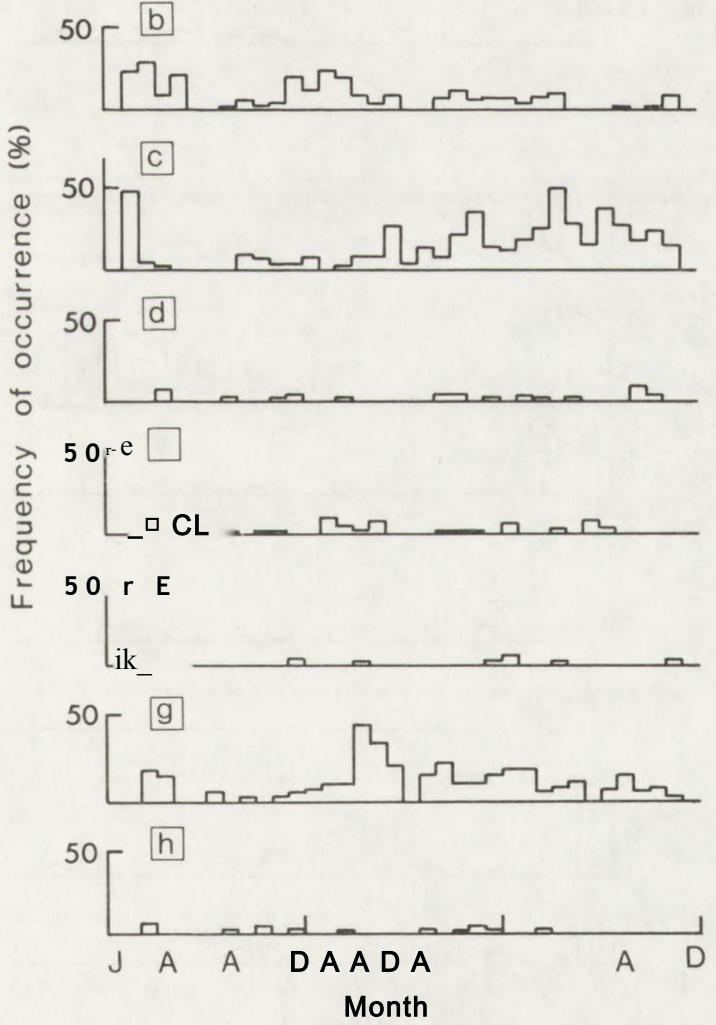

Fig. 4. Frequency of occurrence (\%) of various food categories in the diet of the badger in the Maremma Natural Park between February 1983 and November 1985. a - Annelida, b - Myriapoda, c - Mollusca, d - Amphibia, e - Aves, f - Mammalia, g - Grass, h - Other. 
Mollusca: the monthly frequency of occurrence of molluscs was not correlated with either the monthly mean temperature or the monthly rainfall (Table 1). Moreover, the monthly frequency of occurrence of slugs (Limacidae) was negatively correlated with that of birds (Table 1). The frequency of occurrence of slugs in the diet showed a peak in winter 1983, autumn 1984, and in spring 1985 (Fig. 4c). The estimated volume had values over 5\% throughout 1984 and 1985 (Fig. 5c).

Amphibia: the monthly frequency of occurrence of amphibians was not correlated with both the monthly mean temperature and monthly rainfall (Table 1). Moreover, no correlations were found between the monthly frequency of occurrence of amphibians and that of other food categories. The frequency of occurrence of frogs (Rana spp.) was so low that the seasonal variation in their occurrence could not be analysed statistically. However, they occurred mainly during spring and summer (Fig. 4d), and their presence in the faeces was restricted to single individuals. Accordingly, their estimated volume was always small (Fig. 5d).
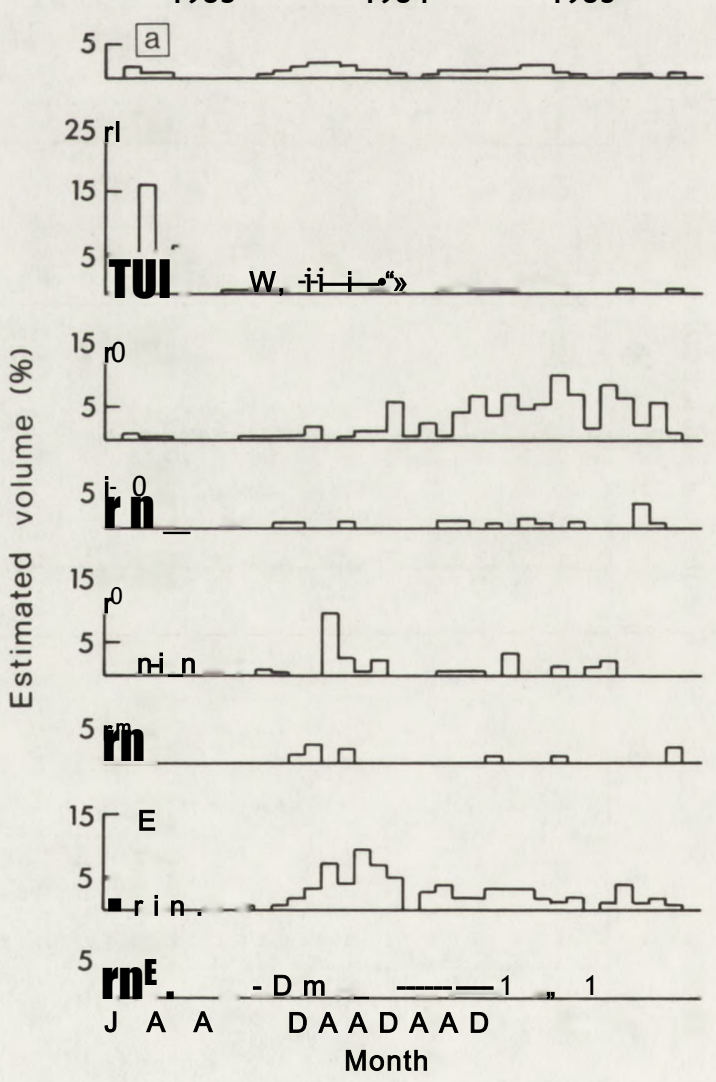

Fig. 5. Estimated volume (\%) of various food categories (legend as in Fig. 4) in the diet of the badger in the Maremma Natural Park between February 1983 and November 1985. 
Aves: the monthly frequency of occurrence of birds was not correlated with either the monthly mean temperature or the monthly rainfall (Table 1). Moreover, the monthly frequency of occurrence of birds was negatively correlated with that of molluscs (Table 1). The frequency of occurrence of birds (mainly Turdus merula and Gallinula chloropus) in the diet was too low to allow any statistical comparison between seasons. However, their occurrence tended to be higher in winter (Fig. 4e). The estimated volume was small in any month (Fig. 5e). Interestingly no remains of game birds were found and eggs occurred on only two occasions.

Mammalia: the monthly frequency of occurrence of mammals was negatively correlated with the monthly mean emperature but not with the monthly rainfall (Table 1). Moreover, the monthly frequency of occurrence of mammals was positively correlated with that of earthworms and myriapods (Table 1). Small rodents (Apodemus sylvaticus and Apodemus flavicollis) were found in the faeces. On two occasions Suncus etruscus were also found. Conversely, rabbits (Oryctolagus cuniculus) were never found in the faeces and on only one occasion remains of Sus scrofa occurred. However, the occurrence of mammals was so low that statistical analyses of their seasonal variation (Fig. 40 were not possible. The estimated volume was small in any month (Fig. 50-

Grass and leaves: the monthly frequency of occurrence of grass and leaves was not correlated with both the monthly mean temperature and the monthly rainfall (Table 1). Moreover, the monthly frequency of occurrence of grass and leaves was positively correlated with that of earthworms (Table 1). This category does not necessarily represent a food resource for badgers, being probably ingested while eating other food resources. Remains occurred in almost any month (Fig. 4h) but the highest values of occurrence and estimated volume were recorded during late winter and spring (Fig. 5h).

Other: the monthly frequency of occurrence of other foods was positively correlated with the monthly rainfall but not with the monthly mean temperature (Table 1). Moreover, the monthly frequency of occurrence of other foods was positively correlated with that of insects, and negatively with that of fruits (Table 1). Lizards \{Lacertidae) were found at the end of summer and early autumn (Fig. 4h). Their contribution to the diet was unimportant both in terms of frequency of occurrence and estimated volume (Fig. 5h).

\section{Discussion}

Overall diet

The diet of the badger in the Maremma Natural Park has two striking characteristics which distinguish it from those of other areas. Firstly, the diet consists mainly of two types of food of equal importance (insects and fruits) which make up a combined volume of about $90 \%$ of the total amount of food eaten in any year. In only one other study were two food resources found to contribute similarly to the bulk of food eaten (i.e. vegetable foods $38 \%$ and earthworms 42\%) (Mouches 1981). In most studies only one food resource made up the bulk of the food eaten by badgers: earthworms (e.g. Andersen 1955, Skoog 1970, Hancox 1973, Wiertz 1976, Kruuk and Parish 1981, Henry 1984) mammals (mainly rabbits) (Martin-Franquelo and Delibes 1985) or fruits (mainly olives) (Kruuk and De Kock 1981). Elsewhere, at least three food resources of equal importance, earthworms, amphibians, and fruits (Ibanẽz and Ibañez 1980) 
or earthworms, fruits, and 'scavenged foods' (Harris 1984) made up the bulk of the diet. The second major difference from other studies was in the small contribution of earthworms in the diet. If one excludes the studies in which the occurrence of earthworms is likely to have been overlooked (e.g. most Russian work, cf. G. Pigozzi, in press), a similar pattern is found only in the Dofiana National Park (Martin-Franquelo 1984; Martin-Franquelo and Delibes 1985). Since the two study areas have similar climatological and environmental conditions, it is reasonable to suggest that the reduced occurrence of earthworms in the diet reflected their low availability in the local habitat (G. Pigozzi, unpublished data). The positive correlation found between the frequency of occurrence in the diet and the latitude of the study areas (G. Pigozzi, in press) also seems to support this suggestion.

\section{Temporal variation in the diet}

The occurrence of most food categories showed a seasonal variation. Insects had the highest frequency of occurrence in spring, fruits and molluses in autumn, earthworms and myriapods in winter, and these patterns were fairly consistent throughout the study. The estimated volume of the most important food categories also varied seasonally, with higher values during winter and spring for insects and during summer and autumn for fruits. Marked seasonal variations in the occurrence of the most important food resource(s) in the diet are not common when badgers feed mainly on only one food resource throughout the year. This may be because badgers increase their foraging effort to compensate for fluctuations in the availability of the most important food resource, as suggested by several authors (e.g. Kruuk and Parish 1981, Martin-Franquelo and Delibes 1985). On the other hand it may be because of a lack of alternative food resources, which are abundant and/or easily accessible to badgers. However, when such an alternative food resource occurred, the most important food resource showed a marked seasonal fluctuation in the amount eaten by badgers. Henry (1984) has found that badgers fed selectively on an alternative food resource (i.e. toads) during early spring when earthworms, their principal food, were still frequently eaten (occurrence in the diet over 90\%). Toads were abundant and probably easily accessible to badgers since they occurred in large numbers around a pond (i.e. breeding area), instead of being dispersed as usual in the forest (Henry 1984). In addition Kruuk and Parish (1985) have shown a remarkable change in the diet of badgers after a variation in the management of agricultural areas in Speyside (Scotland). The area cultivated with barley has increased sharply whereas pastures decreased slightly. At the same time, the density of earthworms declined whereas barley became more abundant and probably more accessible to badgers. As a result the diet showed a significant decline in the volume of earthworms $(20 \%)$ and a marked increase in that of barley (15\%). Yet, the frequency of occurrence of earthworms has not changed very much during this period having a mean yearly value still over 95\%, which may suggest that badgers fed selectively on barley. The finding of a high volume of barley eaten in September - October, the period of highest availability of earthworms (Kruuk and Parish 1985), confirms this suggestion. On the other hand, marked seasonal fluctuations in the exploitation of the most important food resources seem to be the general rule when highly seasonal and abundant food resources play the role of principal components of the diet of badgers (e.g. Mouches 1981, Ciampalini and Lovari 1985, Pigozzi 1988). Mouches (1981) has found that earthworms were the most important 
food resource during winter and spring whereas vegetable foods were during summer and autumn. The seasonal occurrence of the most important food resources in the diet in Mouches' study is remarkably similar to that found in the Maremma Natural Park, the only difference being the substitution of insects for earthworms (Ciampalini and Lovari 1985, this study). Yet, it is also worth pointing out the unusual exploitation of insects during autumn 1985 (Fig. 3), after an extremely hot and dry summer which delayed the ripening of some fruits (e.g. strawberry-tree). It seems therefore reasonable to suggest that, under the above mentioned circumstances, badgers might adjust to their fluctuating food resources by changing their foraging technique (Pigozzi 1989) and/or their food choice so as to maximize their intake from the available food resources.

Acknowledgements: I wish to thank I. Boschi, P. Tonelli and D. Venturi for technical and logistical support throughout the study. E. Banfi, I. Bucciarelli, C. Leonardi, and C. Pesarini helped in the determination of plant and invertebrate species. I thank C. Cheeseman, H. Kruuk, S. Lovari, I. J. Patterson, and P. A. Racey for discussion and helpful comments on earlier versions of the manuscript This research was carried out under tenure of a grant from the Italian Ministry of Education (M.P.I.), to which I am most grateful.

\section{References}

Andersen J. 1955. The food of the Danish badger (Meles meles danicus). Dan. Rev. Game Biol. 3: 1-75.

Arrigoni P. V., Gellini R., Innamorati M., Lenzi Grillini C., Lovari S., Piussi P., Renzoni A., Sanesi G. and

Sartoni G. 1976. Relazione al Consorzio per l'istituzione del Parco della Maremma. Inform. Bot. Ital. 8:

$283-324$.

Blondel J. 1969. Sédentarité et migration des oiseaux dans une garrigue méditerranéenne. Terre et Vie 23: 269-314.

Calver M. C. and Wooller R. D. 1982. A technique for assessing the taxa, length, dry weight and energy content of the arthropod prey of birds. Austr. Wildl. Res. 9: 293 - 301.

Ciampalini B. and Lovari S. 1985. Food habits and niche overlap of the badger (Meles meles L.) and the red fox (Vulpes vulpes L.) in a Mediterranean coastal area. Z. Sàugetierk. 50: 226 - 234.

Day M. G. 1966. Identification of hair and feather remains in the gut and faeces of stoats and weasels. J. Zool. 148: $201-217$.

Debrot S., Fivaz G., Moermod C. and Weber J. M. 1982. Atlas des poiles de mammifères d'Europe. Imprimerie de l'Ouest S. A., Peseux, Switzerland: 1 -208.

Edwards C. A. and Lofty J. R. 1977. Biology of Earthworms. Chapman \& Hall, London.

Hancox M. K. 1973. Studies on the ecology of the Eurasian badger (Meles meles L.). Unpublished report, Elton Library, Oxford.

Harris S. 1984. Ecology of urban badgers Meles meles:_ distribution in Britain and habitat selection, persecution, food and damage in the city of Bristol. Biol. Cons. 28: $301-323$.

Henry C. 1984. Eco-éthologie de l'alimentation du blaireau européen \{Meles meles L.) dans une foret ducentre de la France. Mammalia 48: 489 - 503.

Herrera C. M. 1982. Seasonal variation in the quality of fruits and diffuse coevolution between plants and avian dispersers. Ecology 63: 773 - 785.

Ibañez C. and Ibañez J. I. 1980. Alimentación del tejon \{Meles meles L. 1758) en el Rasillo de Cameros (Logroño España). [In: Actas Ia Reunion Iberoamericana de Zoologos de Vertebrados. J. Castoviejo, ed.]. La Rábida (Huelva), España: 517 - 527.

Kruuk H. 1978. Spatial organisation and territorial behaviour of the European badger, Meles meles. J. Zool., Lond. 184: 1 - 19.

Kruuk H. and De Kock L. 1981. Food and habitat of badgers (Meles meles) on Monte Baldo, northern Italy. Z. Sàugetierk. 46: 295 - 301. 
Kruuk H. and Parish T. 1981. Feeding specialization of the European badger M"les meles in Scotland. J. Aniin. Ecol. 50: 773 - 788.

Kruuk H. and Parish T. 1985. Food, food availability and weight of badgers (Meles meles) in relation to agriculture changes. J. Appl. Ecol. 22: 705 - 715.

Martín-Franquelo R. 1984. La alimentación del tejon Meles meles (L. 1758) en Doñana comparada con la de otras localidades españolas y europeas. [In: Actas $2^{\text {a }}$ Reunión Iberoamericana de Conservación y Zoologia de Vertebrados. J. Castroviejo, ed.]. Cáceres, España: 372 - 377.

Martín-Franquelo R. and Delibes M. 1985. Earthworms or rabbits?: The feeding specialization of the European badger. Abstracts of papers and posters. 4th International Theriological Congress, Edmonton: Abstr. no. 0402.

Mouches A. 1981. Variations saisonnidres du regime alimentaire chez le blaireau européen (Meles meles). Rev. Ecol. 35: 183- 194.

Pigozzi G. 1988. Diet of the European badger (Meles meles L.) in the Maremma Natural Park, Central Italy. Mammal Rev. 18: 73 - 74.

Pigozzi G. 1989. Digging behaviour while foraging by the European badger, Meles meles, in a Mediterranean habitat. Ethology 83: 121 - 128.

Pigozzi G. 1990. Latrine use and the function of territoriality in the European badger, Meles meles, in a Mediterranean coastal habitat. Anim. Behav. 39: 1000 - 1002.

Pigozzi G., in press. Feeding tactics and geographic variation of the diet of the European badger (Meles meles L.). Säugetierk. Mitt.

Skoog P. 1970. The food of the Swedish badger, Meles meles L. Viltrevy 7: 1 - 120.

Toschi A., 1965: La Fauna d'Italia. Mammalia. Edizioni Calderini, Bologna: 1 - 515.

Wiertz J. 1976. De voedsel-ecologie van de das (Meles meles L.) in Nederland. RIN-Rapport 79/9 Rijksinstitut voor Naturbeheer, Leersum.

Received 19 March 1990, revised 1 March 1991, accepted 2 April 1991. 